\title{
Unexpected Southern Hemisphere ionospheric response to geomagnetic storm of 15 August 2015
}

\author{
Ilya Edemskiy ${ }^{1}$, Jan Lastovicka ${ }^{2}$, Dalia Buresova ${ }^{2}$, John Bosco Habarulema ${ }^{3}$, and Ivan Nepomnyashchikh ${ }^{4}$ \\ ${ }^{1}$ Institute of Solar-Terrestrial Physics, SB RAS, Irkutsk, Russia \\ ${ }^{2}$ Institute of Atmospheric Physics CAS, Prague, Czech Republic \\ ${ }^{3}$ South African National Space Agency (SANSA) Space Science, Hermanus, South Africa \\ ${ }^{4}$ Irkutsk State Technical University, Irkutsk, Russia
}

Correspondence: Ilya Edemskiy (ilya@iszf.irk.ru) and Jan Lastovicka (jla@ufa.cas.cz)

Received: 21 June 2017 - Revised: 23 October 2017 - Accepted: 21 November 2017 - Published: 19 January 2018

\begin{abstract}
Geomagnetic storms are the most pronounced phenomenon of space weather. When studying ionospheric response to a storm of 15 August 2015, an unexpected phenomenon was observed at higher middle latitudes of the Southern Hemisphere. This phenomenon was a localized total electron content (TEC) enhancement (LTE) in the form of two separated plumes, which peaked southward of South Africa. The plumes were first observed at 05:00 UT near the southwestern coast of Australia. The southern plume was associated with local time slightly after noontime (1$2 \mathrm{~h}$ after local noon). The plumes moved with the Sun. They peaked near 13:00 UT southward of South Africa. The southern plume kept constant geomagnetic latitude $\left(63-64^{\circ} \mathrm{S}\right)$; it persisted for about $10 \mathrm{~h}$, whereas the northern plume persisted for about $2 \mathrm{~h}$ more. Both plumes disappeared over the South Atlantic Ocean. No similar LTE event was observed during the prolonged solar activity minimum period of 20062009. In 2012-2016 we detected altogether 26 LTEs and all of them were associated with the southward excursion of $\mathrm{Bz}$. The negative $\mathrm{Bz}$ excursion is a necessary but not sufficient condition for the LTE occurrence as during some geomagnetic storms associated with negative $\mathrm{Bz}$ excursions the LTE events did not appear.
\end{abstract}

Keywords. Ionosphere (ionospheric disturbances; midlatitude ionosphere)

\section{Introduction}

The ionospheric variability is to a large extent driven by the solar and geomagnetic activity and is influenced by plasma transport, electric fields and currents, and neutral winds and atmospheric waves (e.g., Prolss, 2004; Kelley, 2009; Rishbeth and Mendillo, 2001). The largest changes in regular ionospheric variability are usually caused by geomagnetic storms. The ionospheric effects of geomagnetic storms have been reviewed by, e.g., Field and Rishbeth (1997), Buonsanto et al. (1999), Lastovicka (2002), Fuller-Rowell et al. (2007) and Danilov (2013). Several decades of ionospheric studies have shown that the ionospheric response to geomagnetic storms can differ above different locations (Yizengaw et al., 2005; Pirog et al., 2006a, b; Habarulema et al., 2013; Buresova and Lastovicka, 2017). Due to the relatively dense global coverage of Global Navigation Satellite System (GNSS) receivers, measurements of the total electron content (TEC) are nowadays used as a key parameter to study the ionospheric response to geomagnetic storms (e.g., Borries et al., 2016; Habarulema et al., 2015; Horvath and Lovell, 2015; Liu et al., 2016) and to describe an impact of the state of ionization of the Earth's upper atmosphere on the radio wave propagation conditions, which is crucial for terrestrial and Earth-space communications. The results of (Yin et al., 2004) demonstrated the potential of the two-dimensional tomographic methods extended to three-dimensional timedependent imaging and applied to ground based GPS observations, which allows GPS data to be used for large-scale studies of the ionosphere under very disturbed geomagnetic conditions. (Afraimovich et al., 2006) carried out a comparative analysis of TEC variations and geomagnetic field variations during the intense magnetic storm of 29-31 October $2003(\mathrm{Kp}=9)$ for the middle-latitude ionosphere over the North American and European region and showed that 
magnetic field intensity variations for the period range of 30-60 min correlated well with TEC variations on the same timescale.

In September 2016, a COSPAR Capacity Building workshop on space weather and its effects on the Earth's system was held in Paratunka, Kamchatka, Russia. During the workshop students were grouped into several teams in order to analyze complex solar-terrestrial events. One team led by Ilya Edemskiy and supervised by Jan Lastovicka was asked to analyze the solar-terrestrial events of August 2015. One of them, the event of 15 August 2015, revealed strong and unexpected localized enhancement of TEC observed near local noon in a region between Africa and Antarctica - i.e., at southern higher midlatitudes. This was a by-product of the requested analysis but a scientifically interesting puzzle. This paper deals with analysis of that puzzle.

Section 2 describes the data and methods used. Section 3 presents results and discussion. Section 4 contains conclusions.

\section{Data and methods}

Geomagnetic indices (Kp and Dst) data used to characterize the general geophysical situation were taken from the NASA Coordinated Data Analysis Web. ${ }^{1}$ Information about coronal mass ejections (CMEs) responsible for the selected storm of August 15 was taken from satellite observations of the Sun. ${ }^{2}$

The ionosphere is primarily characterized by TEC, taken from the Bern (CODE) hourly global ionospheric maps (GIMs) ${ }^{3}$ and from the local South African network TRIGNET. ${ }^{4}$ Radio occultation GNSS electron densities are measured by the FORMOSAT-3/COSMIC constellation. ${ }^{5}$ Polar cap ionospheric drift dynamics was analyzed with $\mathrm{Su}-$ perDARN (Super Dual Auroral Radar Network) data plots obtained from the VirginiaTech University service. ${ }^{6}$ Particle population in radiation belts has been monitored by RBSP (Radiation Belt Storm Probes, now Van Allen satellites) and POES (Polar Observational Environmental Satellites); we use RBSP data. ${ }^{7}$ Data of Grahamstown $\left(33.3^{\circ} \mathrm{S}, 26.5^{\circ} \mathrm{E}\right.$; geomagnetic $41.9^{\circ} \mathrm{S}$ ) and Hermanus $\left(34.4^{\circ} \mathrm{S} ; 19.2^{\circ} \mathrm{E}\right.$; geomagnetic $42.2^{\circ} \mathrm{S}$ ) ionosondes are provided by the South African National Space Agency. ${ }^{8}$ For re-calculation of geographic to geomagnetic coordinates we used Kyoto calculator ${ }^{9}$ for 2015 . To analyze particles precipitation intensity

\footnotetext{
${ }^{1}$ CDAWeb: http://cdaweb.sci.gsfc.nasa.gov

${ }^{2}$ SOHO: ftp://ftp.swpc.noaa.gov/pub/warehouse/2015/

${ }^{3}$ GIM: ftp://ftp.aiub.unibe.ch/CODE/2015/

${ }^{4}$ TRIGNET: ftp://ftp.trignet.co.za

${ }^{5}$ COSMIC: http://cdaac-www.cosmic.ucar.edu

${ }^{6}$ SuperDARN plots: http://vt.superdarn.org/

${ }^{7}$ RBSP: http://rbspgway.jhuapl.edu/

${ }^{8}$ SANSA: https://spaceweather.sansa.org.za/

${ }^{9}$ wdc.kugi.kyoto-u.ac.jp/igrf/gggm/index.html
}

we use the Ovation Prime model available via the Integrated Space Weather Analysis system. ${ }^{10}$

To find local TEC enhancement (LTE) in GIM maps we developed a method based on the analysis of deviations of individual TEC values $I$ from corresponding TEC median values $M_{I}$. The median $M_{I}$ is calculated with a window of 5 days for the given UT maps. Then we calculate the residuals $\Delta M_{I}=I-M_{I}$ and determine the 5-day median values $M_{\Delta}$ from individual values of $\Delta M_{I}$. Finally, we calculate and then analyze the deviations $D=\Delta M_{I}-M_{\Delta}$. If the positive total deviation $D$ for the investigated region exceeds a given threshold, we consider it to be a LTE. A computer code was developed which automates the finding of LTEs based on the above method.

\section{Results and discussion}

To describe the overall solar-terrestrial situation in $\mathrm{Au}-$ gust 2015 we are using geomagnetic indices Kp and Dst. Figure 1 shows that during August 2015 the disturbed geomagnetic conditions occurred around 15 August, 22-23 August and 26-29 August. The event of 22-23 August was weak. The event of 15 August was relatively rapid, which indicates CME origin, whereas the third event was rather slow, which suggests a different origin. Here we shall focus on the event of 15 August, because it was accompanied by an unexpected phenomenon in the Southern Hemisphere ( $\mathrm{SH}$ ) ionosphere.

Solar data confirm the existence of a CME probably responsible for the 15 August geomagnetic storm. The $15 \mathrm{Au}-$ gust geomagnetic storm was induced by the 12 August partial-halo CME, which was visible on SOHO/LASCO C2 imagery. ${ }^{11}$ The CME was found to be Earth-directed. The event was accompanied by a substantial sudden increase of solar wind proton density and a strong negative solar wind magnetic field component $\mathrm{Bz}$ related to the arrival of the CME on 15 August, as shown in Fig. 1. This increase corresponds to the observed geomagnetic storm marked by behavior of Dst. As Fig. 2 shows, no proton events were observed at geosynchronous orbit. The flux of electrons with energies greater than $2 \mathrm{MeV}$ at geosynchronous orbit somewhat dropped during the storm of 15 August. It recovered on 16 August. Dst reached its minimum $(-84 \mathrm{nT}$ at about 08:00 UT, Fig. 1) on 16 August in the second pulse of geomagnetic storm (Fig. 1).

Such a geomagnetic storm should give rise to an ionospheric storm. To investigate the storm-induced ionospheric disturbances, TEC data have been used, because this is the only continuously monitored ionospheric parameter with global and reasonably dense coverage. GIMs of TEC taken from Bern Centre for Orbit Determination in Europe $\left(\mathrm{CODE}^{12}\right)$ data are shown in Fig. 3 for the quiet day of $5 \mathrm{Au}-$

\footnotetext{
${ }^{10} \mathrm{https}$ ://iswa.gsfc.nasa.gov/IswaSystemWebApp/

${ }^{11}$ SOHO: ftp://ftp.swpc.noaa.gov/pub/warehouse/2015/

${ }^{12}$ GIM: ftp://ftp.aiub.unibe.ch/CODE/2015/
} 


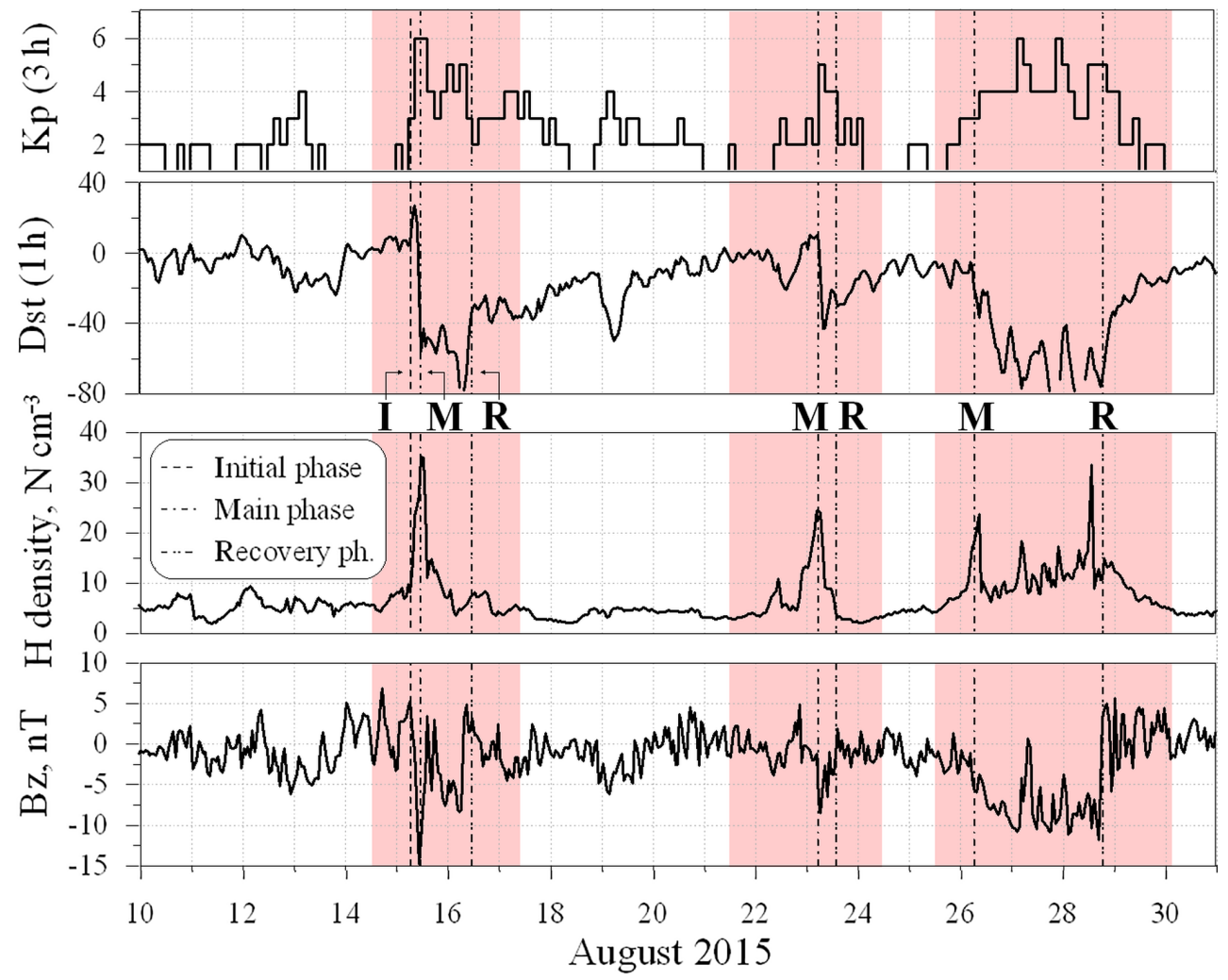

Figure 1. Variation of geomagnetic indices Kp and Dst, and solar wind parameters (proton density and Bz) during August 2015. Colored columns mark the three geomagnetic storms. I, M, R - onset of initial, main and recovery phases of geomagnetic storms, respectively.

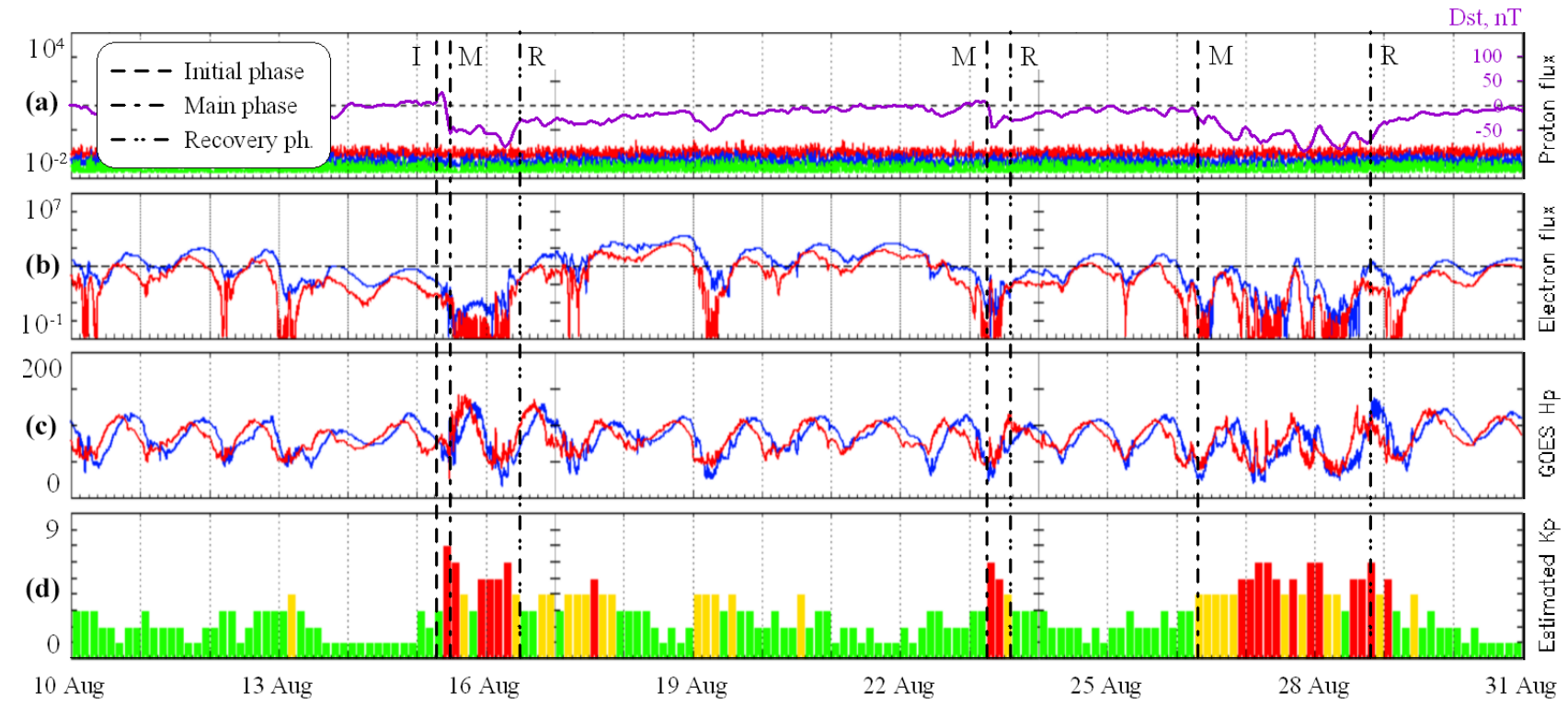

Figure 2. Three-day "satellite environment" around 15 August 2015 (NOAA/SWPC Boulder, CO, USA). Panels from top to bottom: proton fluxes, electron fluxes at geosynchronous altitude, GOES Hp, Kp. I, M, R - onset of initial, main and recovery phases of geomagnetic storms, respectively.

gust and disturbed day of 15 August. Figure 3 clearly documents for 15 August the existence of storm-enhanced TEC at lower latitudes, which is a regular phenomenon, and a strong increase of TEC in the area between Africa and Antarctica. 


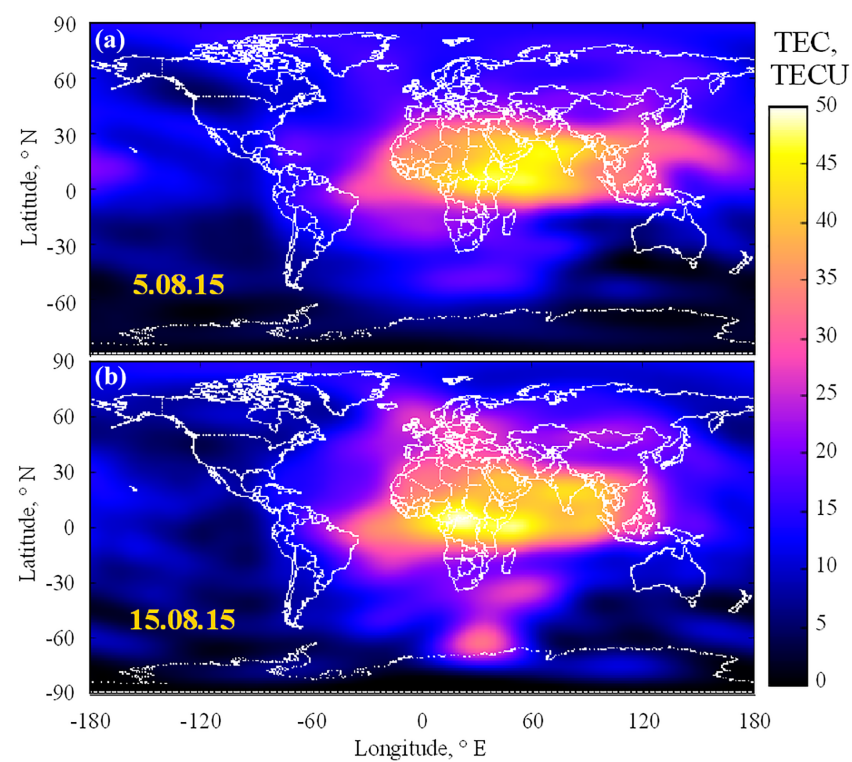

Figure 3. Global total electron density (TEC) distribution at 12:00 UT for the quiet day of 5 August 2015 (a) and the LTE event of 15 August 2015 (b).

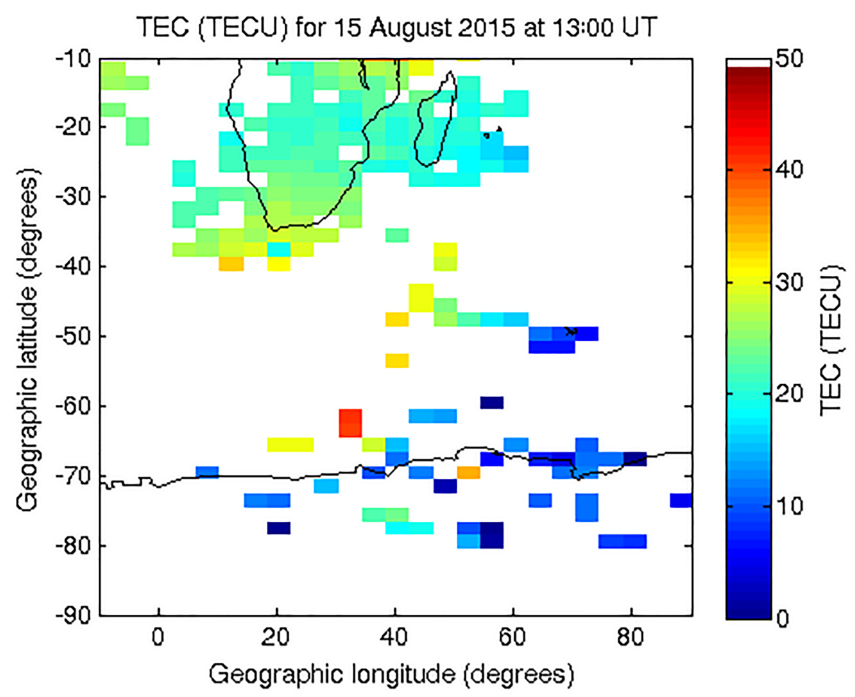

Figure 4. TEC distribution at the Southern Hemisphere based on TRIGNET data.

The investigation of the latter is the objective of our paper. This enhanced TEC area consists of two plumes. One of them is located at lower middle latitudes (central latitude $\sim 35^{\circ} \mathrm{S}$ ) and covers the southernmost Africa and the nearby part of the Indian Ocean. The other plume, which is stronger and the existence of which is more surprising, is located more southward (central latitude $\sim 62-63^{\circ} \mathrm{S}$ ) and it covers an area from the ocean at high middle latitudes to the coast of Antarctica. Figure 4 shows TEC data from the local South African GNSS network TRIGNET. It displays strong enhancement near the Antarctic coast and some enhancement in south-

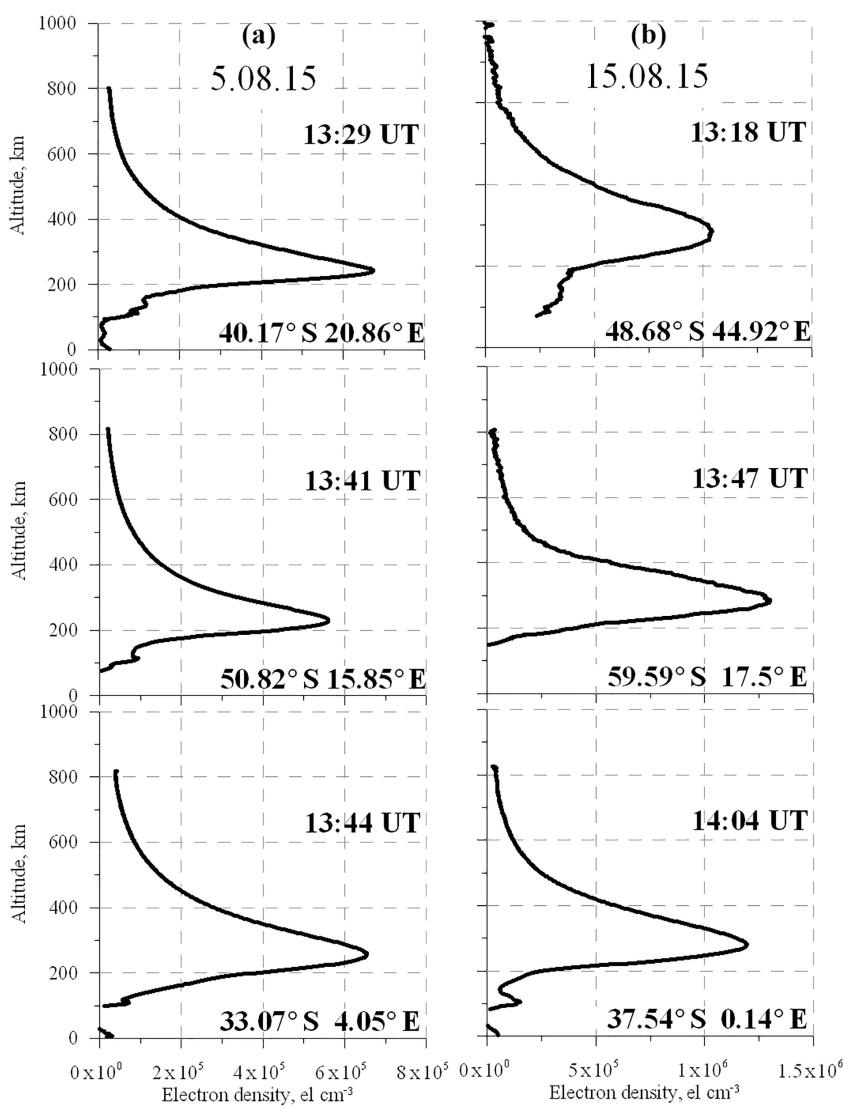

Figure 5. Electron density profiles for the quiet day of $5 \mathrm{Au}-$ gust 2015 (a) and the LTE event of 15 August 2015 (b) by FORMOSART-3/COSMIC data. Note the different electron density scales of left and right panels.

ernmost South Africa with data gaps in between. Thus local South African data confirm the presence of the area of unusually enhanced TEC. Another potential source of ionospheric information from the oceanic area is electron density profiles derived from the FORMOSAT-3/COSMIC radio occultation measurements. These are shown in Fig. 5 (note the different electron density scales of left and right panels). Electron density profiles from the area and time interval of interest show that electron density was much larger there on 15 August than on a typical quiet day of August 2015 for approximately the same times and locations. Two ionosonde stations are located in the area of the northern cell - Grahamstown and Hermanus. At 13:00-14:00 UT of 15 August, electron density observed above both stations was substantially enhanced compared to monthly medians. Figure 6 shows the course of foF2 and $h m F 2$ observed at both stations (red line for Grahamstown and blue one for Hermanus) compared to monthly median of the foF 2 and $h m F 2$ values (black). There is an evident significant enhancement in the maximum electron density ( $f o F 2$ ) at 15 August in both Grahamstown and Hermanus data, which started just after midday. For Grahamstown the increase reaches $42 \%$. We inspected also JASON-2 TEC 

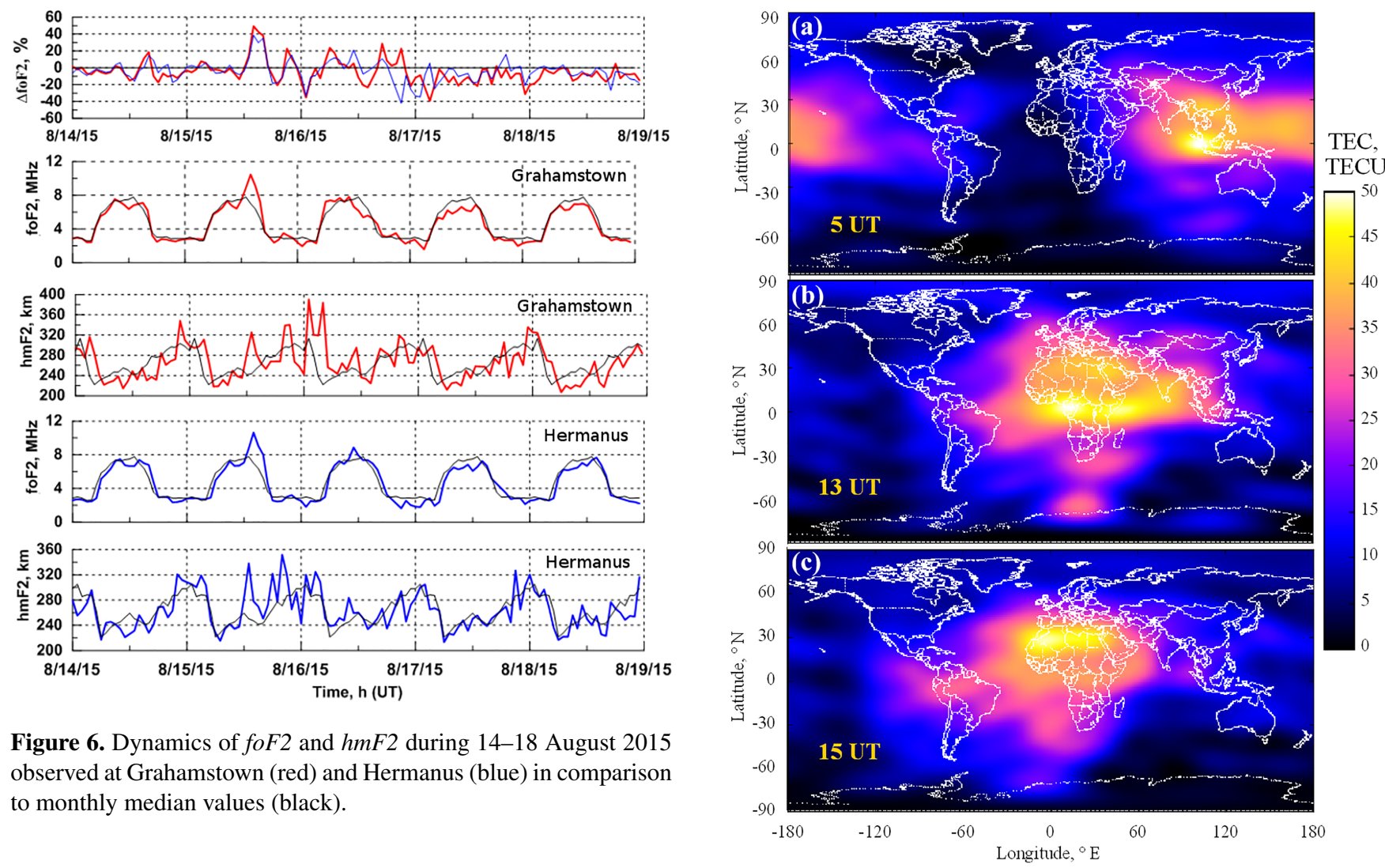

data but in the interval of 11:00-14:00 UT JASON-2 crossed southern higher latitudes in the Pacific Ocean sector, far from the region where TEC plumes occurred.

All the above ionospheric data confirm an anomalous enhancement of electron density in the two plumes between Africa and Antarctica around 12:00 UT. However, how do these two regions evolve with time? We present global CODE TEC maps at 05:00, 13:00 and 15:00 UT in Fig. 7 to demonstrate the development of this enhancement. Figure 7 shows that a weak but detectable enhancement of TEC appears in two plumes at 05:00 UT. The southern plume appears near the southwest coast of Australia (top panel) at longitudes corresponding to early afternoon $(\sim 13: 00 \mathrm{LT})$. The more northern plume is located more westward at $\sim$ 12:00 LT. Maps for 04:00 UT and before do not display such TEC enhancement. Then these two plumes of enhanced TEC move westward with the Sun, reaching maximum near 13:00 UT (middle panel) southward of Africa. The southern plume is centered at $\sim 14: 00 \mathrm{LT}$, the northern one at $\sim$ 15:00 LT. The plumes move further westward with the Sun but the southern plume quickly weakens and the northern plume partly merges with the main storm-related enhancement of TEC at lower latitudes. The southern plume occurs last as a weak trace at 15:00 UT (bottom panel) and the northern plume disappears about $2-3 \mathrm{~h}$ later. Thus the southern plume of enhanced TEC appears to follow local noon - its maximum appears about $2 \mathrm{~h}$ after the local noon ( 14:00 LT), it moves with the Sun, its duration is about

Figure 7. Global hourly TEC maps for the first appearance of the southern higher latitude TEC enhancement plumes (05:00 UT, a), their maximum (13:00 UT, b), and their last appearance (15:00 UT, c).

$10 \mathrm{~h}$ or slightly more, and it occurs only in the Southern Hemisphere. The northern plume moves somewhat slower it is centered at $\sim 12: 00 \mathrm{LT}$ at 05:00 UT but at $\sim 15: 30 \mathrm{LT}$ at 15:00 UT (Fig. 7). Figure 7 also shows that both plumes shift with time to higher geographic latitudes, particularly the southern plume; its center moved from about $54^{\circ} \mathrm{S}$ at 05:00 UT to about $68.5^{\circ} \mathrm{S}$ at 15:00 UT. However, when recalculated to geomagnetic coordinates, which control the horizontal distribution of the ionosphere, the southern plume keeps at an approximately constant geomagnetic latitude of about $63-64^{\circ} \mathrm{S}$. The center of the northern plume even moves to slightly lower geomagnetic latitudes, from about $38.5^{\circ} \mathrm{S}$ at 05:00 UT to about $36^{\circ} \mathrm{S}$ at 15:00 UT.

What might be the reason for the appearance of these two plumes? The Southern Hemisphere has two specific regions, the South Atlantic magnetic anomaly and the Weddell Sea anomaly. However, when approaching the Weddell Sea anomaly, the southern TEC cell rapidly weakens and it disappears within about $2 \mathrm{~h}$. The core of the South Atlantic magnetic anomaly is located more northward but it can affect energetic particle fluxes even at magnetic latitudes corresponding to the southern TEC plume. However, the ionospheric 


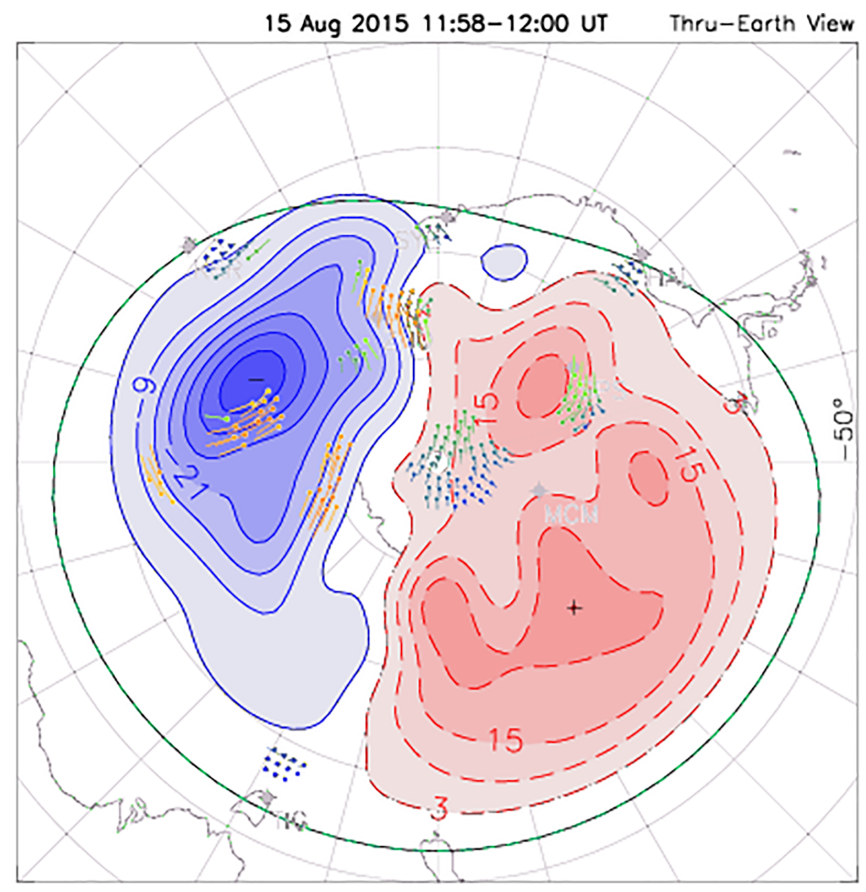

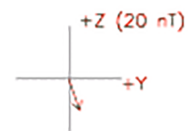

OUNI INF Sto: Mod: RC96
Bz-, $6<8 T<12$

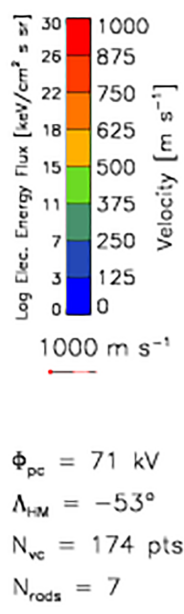

Figure 8. Estimation of polar plasma convection intensity and Heppner-Maynard boundary position $\left(\Lambda_{\mathrm{HM}}\right.$, green line) from the Southern Hemisphere SuperDARN measurements at 12:00 UT on 15 August 2015.

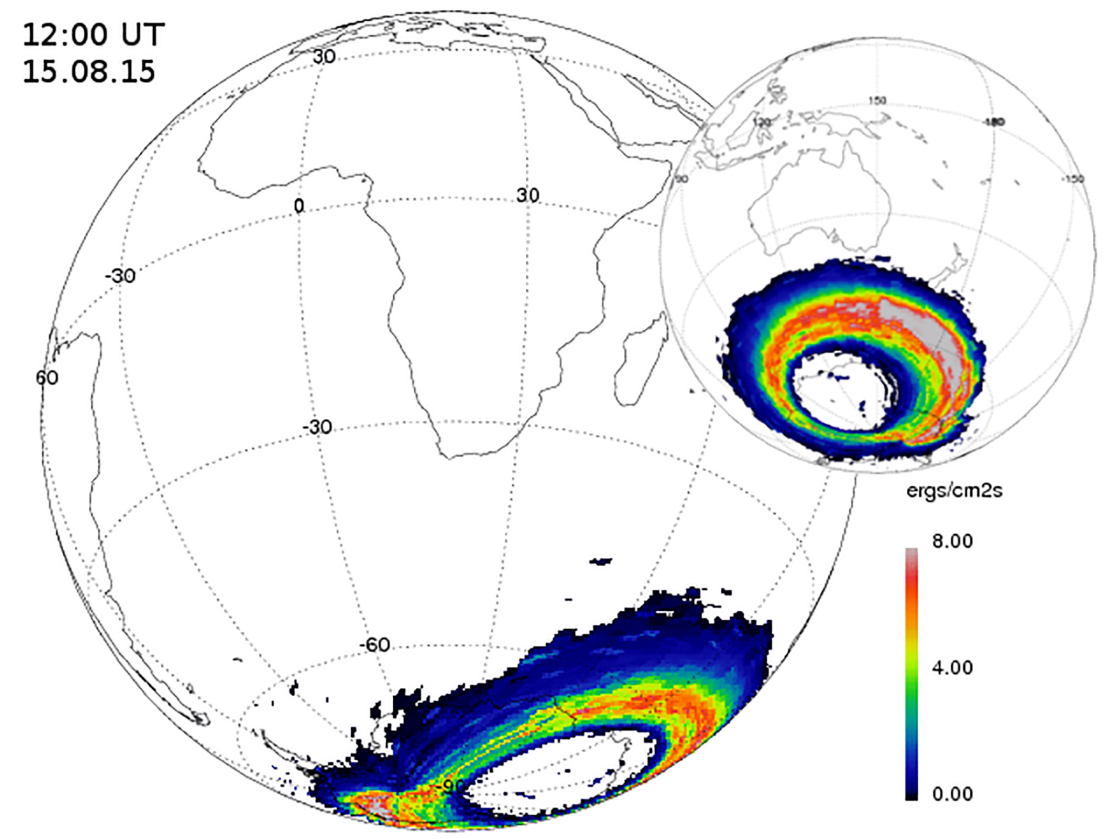

Figure 9. Energy flux of precipitating electrons and ions over the south polar region at 12:00 UT on 15 August 2015 by OVATION Prime data.

anomaly was "born" too eastward to be excited/created by the South Atlantic magnetic anomaly related particle precipitation and other processes.

Conditions in the magnetosphere during the storm period can be analyzed with SuperDARN measurements allowing us to see dynamics of plasma convection over the southern high latitudes. The SuperDARN provides pattern qualitatively expected for such a magnetic storm. Measured velocities show that the most intense convection during the magnetic storm is observed at the same time as the TEC 


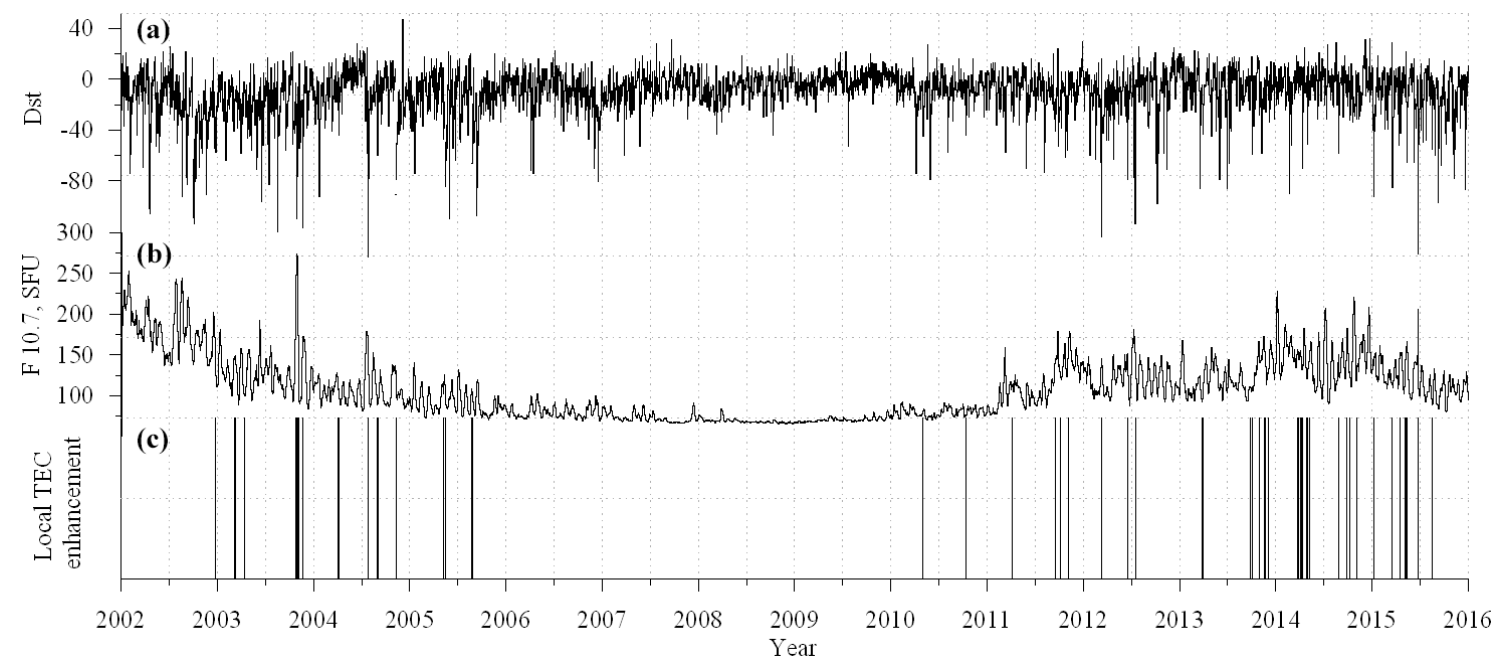

Figure 10. Occurrence of LTEs over the South African midlatitude sector during the period 2002-2015 (c) compared to Dst index (a) and F10.7 index (b).

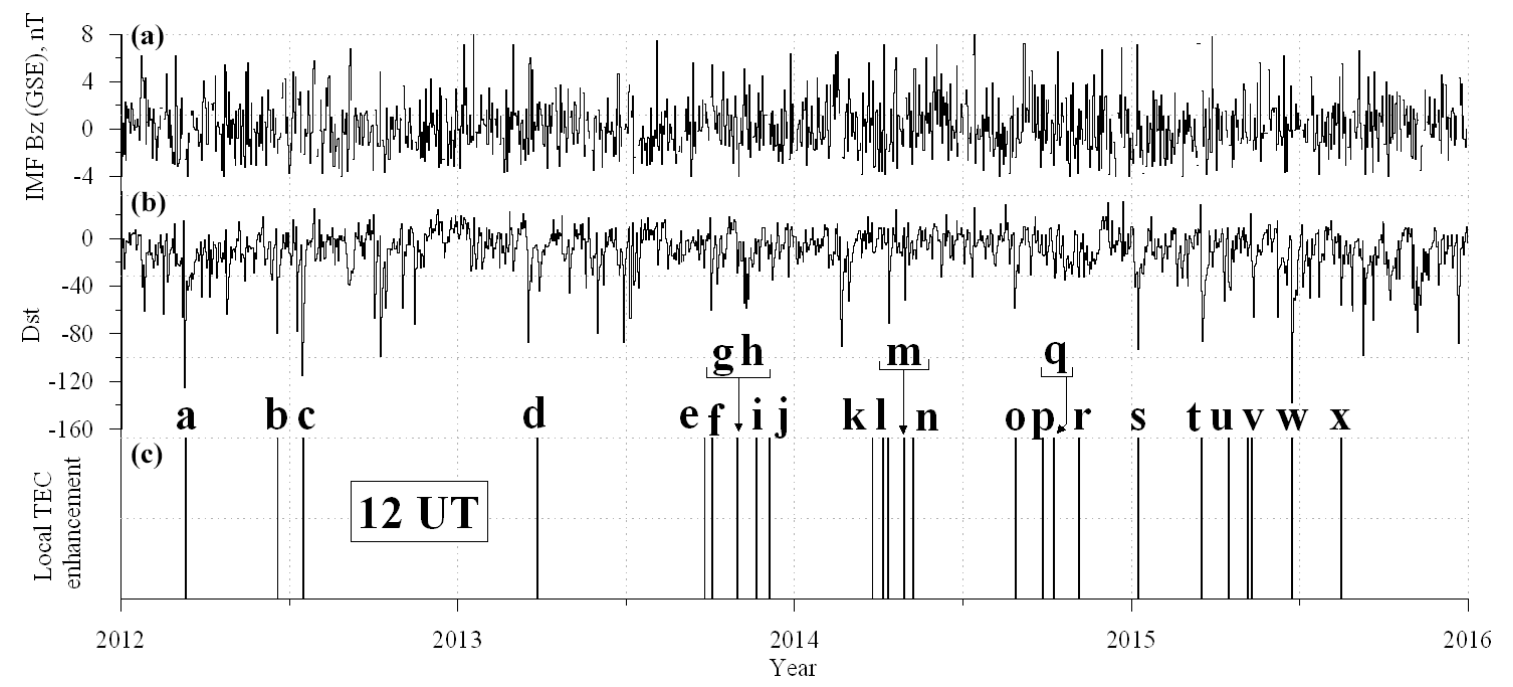

Figure 11. Occurrence of LTEs over the South African midlatitude sector during the period 2012-2015 (c) compared to IMF Z-component $\mathrm{Bz}$ (a) and Dst index (b).

disturbance. Estimated values of a potential across the polar cap are higher than those for the previous days. Figure 8 shows the SuperDARN measurements of plasma velocities and estimated values of electric field potential at 12:00 UT of 15 August. The estimated location of the Heppner-Maynard boundary $\Lambda_{\mathrm{HM}}$ is located lower than in quiet conditions, which allows us to assume some equatorward shift of equatorial boundary of the zone of auroral particle precipitation.

Figure 9 presents the particle flux at 12:00 UT of $15 \mathrm{Au}-$ gust according to the Ovation Prime data. The precipitation zone is located mostly over the Pacific Ocean and it reveals no pronounced flux increase near the center of the southern plume location $\left(\sim 30^{\circ} \mathrm{E}, 62^{\circ} \mathrm{S}\right)$. Any possible ionospheric response to auroral particle precipitation should pronounce itself in other longitudinal sectors and can hardly have any connection with the observed plume. Nevertheless, to be certain, we inspected satellite measurements of high-energy particle fluxes. Satellites RBSP-A and RBSP-B were not in the right time on the right place or its vicinity (corresponding Lshells and magnetic longitudes), therefore they did not provide the requested information. Figure 2 shows other satellite data (from geosynchronous orbit), which indicate no change in proton flux, and some weakening of high-energy electron fluxes that, however, starts $3 \mathrm{~h}$ after the appearance of TEC plumes.

The southern plume is located at relatively high latitudes. So what is its position with respect to the auroral oval? OVATION map (Fig. 9) shows that the center of the southern 
plume at $12 \mathrm{UT}\left(\sim 62^{\circ} \mathrm{S}, \sim 21.5^{\circ} \mathrm{E}\right)$ is located out of the auroral oval, even though by only a little, and in the sector where the auroral oval activity is weaker than in other sectors. A similar conclusion is valid for 13:00 UT. So the plume itself does not seem to be an auroral oval-related phenomenon.

We showed above that LTEs observed in GIMs have also been observed by ionosondes and by COSMIC electron density profiles, at least in the South African region. So we can rely on GIMs to make preliminary conclusions on the LTE occurrence rate and when looking on other possible LTE events. Above, we analyzed one event associated with magnetic storm of 15 August 2015. Now we shall search for the possible occurrence of other LTE events.

Using the method described in Sect. 2 we analyzed GIMs for the period 2002-2016 to find LTEs over the South African midlatitude sector. Figure 10 presents variations of the Dst index (top panel) and of F10.7 (middle panel), and days of detected LTEs (bottom panel). It is evident from Fig. 10 that LTEs occur only during higher solar activity periods. We have not detected any LTE during the low solar activity period 2006-2009. It is important to notice that not all the strong negative Dst events (Dst $<-80 \mathrm{nT}$ ) are accompanied by LTE - i.e., the presence of geomagnetic storm appears to be a necessary but not sufficient condition for the LTE occurrence. Figure 11 shows in more detail the period 20122016: IMF $Z$-component (top panel), Dst variations (middle panel) and LTE occurrence (bottom panel). Bz and Dst values and GIM data are taken for 12:00 UT of each day. The LTE occurrence statistics reveal no pronounced dependence of LTE occurrence on season. All the observed LTE events coincide with negative excursions of Dst but of different magnitude. There are altogether 26 LTE events for the period 2012-2015 marked $a-x$ ( $l$ and $v$ in Fig. 11 mark two very close events each; further on $l_{1}, l_{2}, v_{1}$ and $v_{2}$ ). Three out of 26, events $a, c$ and $w$, are associated with strong magnetic storms Dst $<-100 \mathrm{nT}$. Half of the events (13) are associated with moderate geomagnetic storms (Dst between -50 and $-100 \mathrm{nT})$, events $b, d, f, g, h, l_{2}, m, o, s, t, u, v_{2}, x$. Seven events $(e, i, j, n, p, q, r)$ are associated with weak magnetic storms (Dst between -20 and $-40 \mathrm{nT}$ ). Three events $\left(k, l_{1}\right.$, $v_{1}$ ) are linked to weak but clear negative excursions of Bz between -10 and $-20 \mathrm{nT}$. Thus the negative excursion of Dst appears to be the necessary condition for the occurrence of LTE event. However, it is not sufficient condition, because Fig. 11 shows several moderate and one strong storm (mid2013), when the LTE did not occur.

\section{Conclusions}

Ionospheric effects were investigated during a moderate geomagnetic storm of 15 August 2015, which was probably caused by a CME of 12 August. An unexpected localized TEC enhancement (LTE) in the form of two plumes centered southward of Africa, observed slightly after noontime, was confirmed by all available ionospheric measurements. The event began at 05:00 UT near the southwestern coast of Australia. It was associated with local time slightly after noontime. The southern plume moved with the Sun (the northern plume slightly slower), it peaked near 13:00 UT southward of South Africa, and it disappeared after about $10 \mathrm{~h}$ (the northern plume $2 \mathrm{~h}$ later) over the South Atlantic Ocean. A similar LTE does not occur in the Northern Hemisphere, it is a Southern Hemisphere phenomenon. Its origin is not understood yet.

Analysis of GIMs over the period 2002-2015 shows no occurrence of LTE events during the solar activity minimum period 2006-2009. In 2012-2015 we found altogether 26 LTEs and all of them were associated with a southward excursion of Bz. However, the negative Bz excursion is a necessary but not sufficient condition as during some geomagnetic storms associated with the negative $\mathrm{Bz}$ excursions the LTE events did not appear.

Future work will include a deeper analysis of collected data set of LTE events for 2002-2015, particularly towards finding physical processes behind the occurrence of LTEs. Figure 3 shows a very weak two-plume structure at somewhat lower latitudes and slightly different longitudes for the quiet day of 5 August; therefore a possible quiet-time effect will also be investigated.

Data availability. Geomagnetic indices: http://cdaweb.sci.gsfc. nasa.gov. CME information: ftp://ftp.aiub.unibe.ch/CODE/2015/. Global TEC Bern: ftp://ftp.unibe.ch/aiub/CODE/2015/. South African TEC TRIGNET: ftp://ftp.trignet.co.za. South African ionosonde data: https://spaceweather.sansa.org.za/. Radio occultation COSMIC electron densities: http: //cdaac-www.cosmic.ucar.edu. SuperDARN data plots: http://vt.superdarn.org/.

Author contributions. IE did most of the work; JL came up with the leading idea and substantially contributed to writing the paper; DB analyzed and interpreted ionosonde data, prepared Fig. 5 and contributed to writing the final version; JBH analyzed and interpreted TRIGNET TEC data, prepared Fig. 3 and contributed to writing the final version; and IN helped with data mining and evaluation.

Competing interests. The authors declare that they have no conflict of interest.

Acknowledgements. Authors thank David John McComas at SWRI, Joseph H. King and Natalia Papitashvilli at ADNET, NASA GSFC and CDAWeb for providing space weather data (http:// cdaweb.sci.gsfc.nasa.gov/). We thank John Michael Ruohoniemi from Virginia Tech for his help with SuperDARN data interpretation. The work was done within the COSPAR Capacity Building Fellowship program and supported by a grant of the Russian Federation President (grant no. MK-1097.2017.5). Some of the re- 
sults are obtained with methods and programs developed under the Program of the Fundamental Research of the State Academies of Russia for years 2013-2020, project II.16.1.4 (no. AAAA-A16116120610103-4).

The topical editor, Ana G. Elias, thanks two anonymous referees for help in evaluating this paper.

\section{References}

Afraimovich, E. L., Astafieva, E. I., Voeykov, S. V., Tsegmed, B., Potekhin, A. P., and Rasson, J. L.: An investigation of the correlation between ionospheric and geomagnetic variations using data from the GPS and INTERMAGNET networks, Adv. Space Res., 38, 2332-2336, 2006.

Borries, C., Mahrous, A. M., Ellahouny, N. M., and Badeke, R.: Multiple ionospheric perturbations during the Saint Patrick's Day storm 2015 in the EuropeanAfrican sector, J. Geophys. Res.-Space, 121, 11333-11345, https://doi.org/10.1002/2016JA023178, 2016.

Buonsanto, M. J.: Ionospheric storms - A review, Space Sci. Rev., 88, 563-601, 1999.

Buresova, D. and Lastovicka, J.: Differences in midlatitude ionospheric response to magnetic disturbances at Northern and Southern Hemispheres and anomalous response during the last extreme solar minimum, in: Ionospheric Space Weather: Longitude and Hemispheric Dependences and Lower Atmosphere Forcing, AGU Geophys, Monograph, edited by: Fuller-Rowell, T., Yizengaw, E., Doherty, P. H., and Basu, S., J. Wiley\&Sons, Chap. 4, 41-58, 2017.

Coordinated data analysis Web (CDAWeb): http://cdaweb.sci.gsfc. nasa.gov.

COSMIC Data Analysis and Archive Center: http://cdaac-www. cosmic.ucar.edu.

Danilov, A. D.: Ionospheric F region response to geomagnetic disturbances, Adv. Space Res., 52, 343-366, https://doi.org/10.1016/j.asr.2013.04.019, 2013.

Field, P. R. and Rishbeth, H.: The response of the ionospheric F2layer to geomagnetic activity: an analysis of worldwide data, J. Atmos. Sol.-Terr. Phys., 59, 163-180, 1997.

Fuller-Rowell, T., Codrescu, M., Maruyama, N., Fredrizzi, M., Araujo-Pradere, E., Sazykin, S., and Bust, G.: Observed and modeled thermosphere and ionosphere response to superstorms, Radio Sci., 42, RS4S90, https://doi.org/10.1029/2005RS003392, 2007.

Geomagnetic coordinates calculator (WDC, Kyoto): wdc.kugi. kyoto-u.ac.jp/igrf/gggm/index.html.

Global Ionosphere Maps (GIMs) Produced by CODE: ftp://ftp.aiub. unibe.ch/CODE/2015/.

Habarulema, J. B., McKinnell, L.-A., Buresova, D., Zhang, Y., Seemala, G., Ngwira, C., Chum, J., and Opperman, B.: A comparative study of TEC response for the African equatorial and mid-latitudes during storm conditions, J. Atmos. Sol.-Terr. Phys., 102, 105-114, 2013.
Habarulema, J. B., Katamzi, Z. T., and Yizengaw, E.: First observations of poleward large-scale traveling ionospheric disturbances over the African sector during geomagnetic storm conditions, J. Geophys. Res.-Space, 120, 6914-6929, https://doi.org/10.1002/2015JA021066, 2015.

Horvath, I. and Lovell, B. C.: Positive and negative ionospheric storms occurring during the 15 May 2005 geomagnetic superstorm, J. Geophys. Res.-Space, 120, 7822-7837, https://doi.org/10.1002/2015JA021206, 2015.

Integrated Space Weather Analysis (ISWA) Application: https:// iswa.gsfc.nasa.gov/IswaSystemWebApp/.

Kelley, M. C.: The Earth's Ionosphere, Plasma Physics and Electrodynamics, 2nd Edn., Elsevier, 2009.

Lastovicka, J.: Monitoring and forecasting of ionospheric space weather - effects of geomagnetic storms, J. Atmos. Sol.-Terr. Phys., 64, 697-705, 2002.

Liu, W., Xu, L., Xiong, C., and Yu, J.: The ionospheric storms in the American sector and their longitudinal dependence at the northern middle latitudes, Adv. Space Res., 59, 603-613, https://doi.org/10.1016/j.asr.2016.10.032/, 2016.

Pirog, O. M., Polekh, N. M., Zherebtsov, G. A., Smirnov, V. F., Shi, J. K., and Wang, X.: Seasonal variations of the ionospheric effects of geomagnetic storms at different latitudes of East Asia, Adv. Space Res., 37, 1075-1080, 2006a.

Pirog, O. M., Polekh, N. M., Tashchilin, A. V., Romanova, E. B., and Zherebtsov, G. A.: Response of ionosphere to the great geomagnetic storm of September 1998: Observation and modeling, Adv. Space Res., 37, 1081-1087, 2006b.

Prolss, G. W.: Physics of the Earth's Space Environment, Springer, Berlin, Heidelberg, Germany, 2004.

Rishbeth, H.and Mendillo, M.: Patterns of F2 layer variability, J. Atmos. Sol.-Terr. Phys., 63, 1661-1680, https://doi.org/10.1016/S1364-6826(01)00036-0, 2001.

Solar and Heliospheric Observatory (SOHO) data: ftp://ftp.swpc. noaa.gov/pub/wareh.

TRIGNET GNSS network data: ftp://ftp.trignet.co.za.

South African National space agency (SANSA): https: //spaceweather.sansa.org.za/.

SuperDARN Data Plotting Tools: http://vt.superdarn.org/.

Van Allen Probes (RBSP) science gateway: http://rbspgway.jhuapl. edu/.

Yin, P., Mitchell, C. N., Spencer, P. S. J., and Foster, J. C.: Ionospheric electron concentration imaging using GPS over the USA during the storm of July 2000, Geophys. Res. Lett., 31, L12806, https://doi.org/10.1029/2004GL019899, 2004.

Yizengaw, E., Dyson, P. L., Essex, E. A., and Moldwin, M. B.: Ionosphere dynamics over the Southern Hemisphere during the 31 March 2001 severe magnetic storm using multiinstrument measurement data, Ann. Geophys., 23, 707-721, https://doi.org/10.5194/angeo-23-707-2005, 2005. 